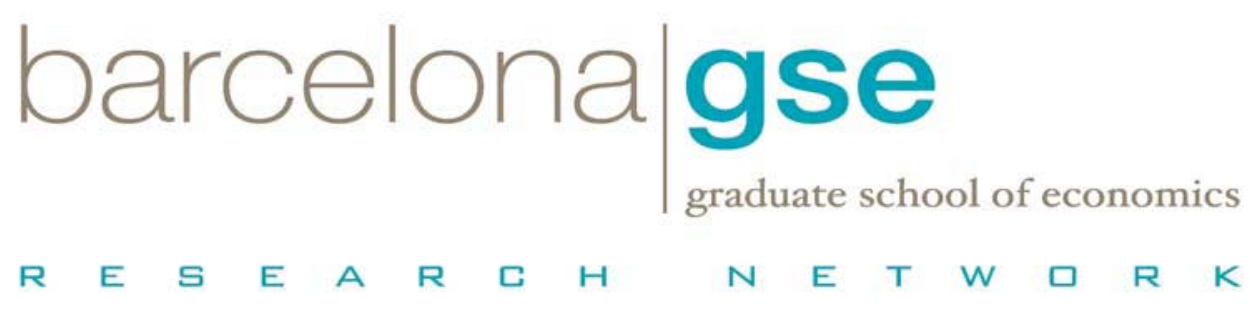

On borrowing limits and welfare

Francesc Obiols-Homs

October 14, 2009

Barcelona Economics Working Paper Series

Working Paper $n^{\circ} 401$ 


\title{
On Borrowing Limits and Welfare
}

\author{
Francesc Obiols-Homs *
}

October 2009

\begin{abstract}
We study the effect of borrowing limits on welfare in several versions of exchange and production economies. There is a "quantity" effect of a larger borrowing limit which is beneficial for liquidity constrained agents, but essentially irrelevant otherwise. There is also a "price effect" which tends to increase the interest rate so that lenders are better off and borrowers are worse off. The combination of these effects produces that aggregate welfare in equilibrium (or ex ante welfare) displays an inverted U-shape as a function of the borrowing limit. In infinite horizon economies with incomplete markets we find a sizable "middle class" of not liquidity constrained but indebted agents that observes small gains, or even loses, after the borrowing limit is enlarged.
\end{abstract}

KEYWORDS: Borrowing constraints, incomplete markets, welfare. JEL Classification: D52, D58, J22

*Department of Economics and Economic History, Universitat Autònoma de Barcelona, E-mail: francesc.obiols@uab.es. Previous versions of this paper circulated under the title "A Note on Borrowing Limits and Welfare". I would like to thank helpful comments and suggestions from J. Caballe, E. Carceles, J.C. Conesa, A. Diaz, T. Keister, A. Marcet, F. Perri, C. Urrutia, seminar participants of the Macroeconomics Workshop at UAB, the SED 2007 meeting in Prague, and specially, from D. Krueger and from two anonymous referees of this journal. The usual disclaimer applies. Financial support from Programa Ramón y Cajal, the Spanish Ministry of Science and Innovation through grant ECO2009-09847, the Barcelona Graduate School Research Network, and the Generalitat of Catalonia through grant 2009SGR-350 is gratefully acknowledged. 


\section{Introduction}

In this paper we study the effects on welfare of institutionally fixed borrowing limits. The usual economic intuition based on efficiency considerations would unambiguously advocate for loosening tight borrowing constraints, since they may prevent achieving fully efficient allocations by limiting the amount of inter temporal trade. The interest in this research comes from the fact that, contrary to this view, we show in a variety of environments that too large borrowing limits may have perverse effects on welfare.

The intuition for the results is as follows. We decompose the effect of changes in the borrowing limit into a "quantity effect" and a "price effect". In particular, an increase in the borrowing limit has a positive quantity effect whenever it effectively alleviates the borrowing constraint, but it is negligible when the constraint does not bind. Hence, the strength of the quantity effect on the welfare of a particular agent depends on how much stringent is the borrowing constraint given her assets and other sources of income. The price effect is due to the fact that in general-equilibrium prices adjust to clear the markets. If a larger volume of debt is the result of allowing more borrowing, then we would expect a larger return to saving in order to clear the assets market. Therefore the usual price effect after an increase in the borrowing limit is positive for savers but negative for borrowers. It follows that the effects of increasing the borrowing limit may be very different across individuals, depending not only on the limit itself but also on their income and wealth levels.

In section 2 we formalize these ideas in a two-period model of exchange with an exogenous distribution of borrowers and lenders. The only potential friction embedded in this environment is a borrowing limit. We show that lenders always gain with the increase in the borrowing limit, and yet, borrowers may loose if the initial borrowing limit is sufficiently large. Furthermore, the welfare loses of the borrowers would be even larger if the borrowing limit is increased up to the level it is not binding anymore. In terms of the intuition stated above, a large borrowing limit reduces the quantity effect and makes relatively stronger the price effect, which sooner or latter dominates the effect on the welfare of borrowers. We conclude that in this simple environment the welfare of borrowers displays an inverted U-shape as a function of the borrowing limit. Interestingly, a too large borrowing limit may be undesirable from the point of view of the borrowers, and yet, should it be implemented it would be exhausted. We also aggregate welfare by means of a utilitarian social welfare function and show that this measure 
of welfare may decrease after the borrowing limit is increased. Therefore, in the ex ante welfare sense all agents may gain by fixing a binding borrowing limit rather than a too loose one. This result is formally proved under mild assumptions, thus an implication of this analysis is that the optimal borrowing limit is, in fact, a binding constraint.

In section 3 we extend the previous analysis by studding similar issues but using quantitative methods in multi period economies in which the distribution of agents is endogenously determined. Specifically, we explore exchange and production economies characterized by incomplete insurance against idiosyncratic shocks (as in Huggett 1993, 1997, Aiyagari 1994, and Krusell and Smith 1998, among many others). In this analysis the measure of welfare we use is the amount of consumption required to leave each agent indifferent between before and after the borrowing limit has increased. Furthermore, we compute measures of consumption equivalent units to compare steady states and also taking into account the transition between them.

We find that a larger borrowing limit tends to benefit agents that were liquidity constrained in the initial equilibrium. These agents gain because of the positive quantity effect. We also find that rich households, for whom the borrowing limit is essentially irrelevant, also benefit from the higher return on their saving observed after the increase in the borrowing limit. ${ }^{1}$ Hence these agents gain because of the positive price effect we mentioned before. Finally, we also find a sizable fraction of poor agents that are not liquidity constrained (and thus do not benefit especially from having access to larger credit) that tend to suffer because they hold debt (which is more costly after the increase in the interest rate). The final effect on the welfare of these agents and on the size of this category, which we informally label as "middle class", depends on the specifics of each example. For instance, in an exchange economy the middle class may represent above $85 \%$ of the population, and they may observe an average loss of $3 \%$ of consumption (once the transition is properly taken into account). In our version of the production economy calibrated to the U.S. economy the middle class represents over $40 \%$ of the population, and the losses in consumption rang between $0.01 \%$ -when we increase the borrowing limit from roughly a $27 \%$ of per capita assets up to a $57 \%$ - and $3 \%$ of consumption when the borrowing limit is further increased up to $73 \%$ of per capita assets.

Our paper is closely related to Japelli and Pagano (1999), where similar

\footnotetext{
${ }^{1}$ This kind of general equilibrium effect is similar to that explored in Conesa and Krueger (1999), showing that removing social security may, in fact, benefit poor workers that mainly have labor income and hold a low level of assets.
} 
results are obtained relying on the finite lives of agents and on the dynamic efficiency of the economy when technological progress is endogenous. Also, Chaterjee et al. (2002), Mateos-Planas and Seccia (2006), Livshits et al. (2007), and Ábrahám and Cárceles-Poveda (2007) study the endogenous determination of borrowing constraints and their interaction with participation constraints in economies with incomplete insurance markets against idiosyncratic shocks. We contribute to this literature by showing that negative welfare effects may be an intrinsic feature of too large borrowing limits. ${ }^{2}$

Our results are also related to a different strand of the literature which takes the borrowing limit as given and studies the consequences for welfare of allowing some form of bankruptcy at the household level. This is in principle an important difference with respect to our approach, since in our model default is not an option and thus agents honor their debts irrespectively of their wealth and idiosyncratic endowment. To be more precise, Athreya (2002) finds that in an exchange economy eliminating the bankruptcy option would promote such a reduction in deadweight losses that it would outweigh the welfare looses due to less favorable consumption smoothing opportunities. In view of this, our results for exchange economies extend those in Athreya (2002) by showing that a welfare loss would be materialized by fixing a too large borrowing limit even if no default is allowed and non-pecuniary costs are absent from the analysis. Related to this, $\mathrm{Li}$ and Sarte (2006) study similar issues in a production economy and they find that welfare would decrease with the elimination of bankruptcy. The reason why welfare is larger with the default option is that in their model there is over accumulation of capital with respect to the level one would observe if bankruptcy was impossible. That is, in their model default increases the risk premium in a intermediation sector, which reduces the amount of debt and increases the stock of capital. Under the usual assumptions on the technology for production more capital makes labor more productive, and thus, the economy ends up with larger production and consumption. ${ }^{3}$ Contrary

\footnotetext{
${ }^{2}$ The literature about the various effects stemming from borrowing constraints is large. See, among others, Zeldes 1989, Deaton 1991, Attanasio and Weber 1995, Chamberlain and Wilson 2000, Carroll 1994, 2000 (for effects on consumption), Bencivenga and Smith 1991, Marcet and Marimon 1992, Banerjee and Newman 1993, Ljungqvist 1993, Japelli and Pagano 1994 (for related effects on growth and development), Mookherjee and Ray 2002 (dynamics of inequality), Paxson 1990, Lucas 1994, Alvarez and Jermann 2000, 2001, Haliassos and Hassapis 2001 (for implications for assets prices and portfolio choice), and Pratap and Rendon 2003 (about firm's investment).

${ }^{3}$ This may seem paradoxical because it suggests that there are welfare gains associated to the introduction of a policy that takes the competitive allocation further away from the first best allocation (the competitive allocation with incomplete markets is already
} 
to these results, in our production economy we obtain that the losses steam from too little capital when the borrowing limit is enlarged. ${ }^{4}$ This is due to the fact that in our model default is not an option, and thus, no (costly) intermediation is needed.

Finally, there is a connection between our work and the work of Davila et al. (2005). These authors study the notion of constrained efficiency for incomplete markets economies and conclude that in general, there is no reason to expect that the equilibrium allocation is the same one a hypothetical benevolent planner facing the same constraints and competitive price setting would have chosen. For instance, using a model economy calibrated to mimic key observations of the U.S. economy, these authors find that the constrained-efficient amount of capital is about 14.7 units, whereas the competitive amount is about 4 units. When we do steady state comparisons of welfare under several borrowing limits for the same economy, we find that the optimal lower bound for asset holdings is positive (hence no borrowing is allowed). Specifically, the positive optimal lower bound implies an average assets holdings of about 6.3 units of capital. This finding is interesting from a policy perspective, because it suggests that simple policy instruments like a lower bound on assets will not be able to implement the constrained efficient allocation.

The rest of the paper is organized as follows. Section 2 introduces the twoperiod model and states a few results at a formal level, section 3 considers the infinite horizon economies and reports the results from numerical simulations, and section 4 concludes. All proofs are relegated to the Appendix.

\section{A simple model of consumption smoothing}

To develop the intuition for the results in its simplest form, we consider an exchange economy in which a continuum (mass one) of agents live for two periods. The endowments of the consumption good in each period can be either "high" or "low", with $0<e_{t}^{l}<e_{t}^{h}$ for $t=1,2$, and we let $\pi_{t} \in(0,1)$ be the probability of receiving the high endowment in period

characterized by a larger amount of capital than in the first best (Huggett 1993, Aiyagari 1994)). Nevertheless, Hart (1975), Grossman (1977), and more recently Gimenez (2003), can be seen as examples of the fact that alleviating a constraint in incomplete market economies does not necessarily result in larger welfare.

${ }^{4}$ In this regard, our results are more in line with those in Ábrahám and Cárceles-Poveda (2007) 
$t=1,2$. Agents can smooth out their consumption over time by trading a safe asset. We think of this asset as a riskless bond. Specifically, a positive amount of this asset in the end of the first period indicates that the agent is a saver, and each unit of assets is a sure claim to $1+R$ units of consumption goods in the second period. Borrowing is indicated by a negative amount of assets, and it is allowed up to an exogenous limit $-B$. We preclude the possibility of default, hence debt issues in the first period convey the unavoidable obligation of delivering the $1+R$ units of consumption goods in the second period per unit of debt. Finally, we assume that all consumers have the same instantaneous preferences over consumption goods, which are represented with a twice differentiable function $u(c)$ satisfying:

A1: $u$ is $C^{2}$ on $R_{++}$, and it is strictly increasing and strictly concave, with $\lim _{c \rightarrow 0} u^{\prime}(c) \rightarrow+\infty$ and $\lim _{c \rightarrow+\infty} u^{\prime}(c)=0$.

A. The deterministic case

We begin by specializing the previous setting to obtain a deterministic environment. To this end, let $\bar{e}=\pi_{2} e_{2}^{h}+\left(1-\pi_{2}\right) e_{2}^{l}$, normalize $\pi_{1}=1 / 2$, and assume that agents start trading once the endowment in the first period is known. ${ }^{5}$ Given initial endowments and the return $R$, the problem of a given (type of) agent reduces to choosing how much to save or dissave in assets. Formally, the utility maximization problem as a function of $B$ for $i=l, h$ is given by:

$$
\begin{aligned}
\max _{a^{i}} v_{i}(B)= & u\left(c_{1}^{i}\right)+\beta u\left(c_{2}^{i}\right) \\
\text { s. to } & c_{1}^{i}+a^{i}=e_{1}^{i}, \\
& c_{2}^{i}=\bar{e}+(1+R) a^{i}, \\
& c_{1,2}^{i} \geq 0, a^{i} \geq-B,
\end{aligned}
$$

where $\beta \in(0,1)$ is the discount rate of future utility. The solution of the previous problem is characterized by the usual first order conditions:

$$
\begin{aligned}
& u^{\prime}\left(c_{1}^{i}\right)=\beta(1+R) u^{\prime}\left(c_{2}^{i}\right) \quad \text { if } a^{i}>-B, \\
& u^{\prime}\left(c_{1}^{i}\right) \geq \beta(1+R) u^{\prime}\left(c_{2}^{i}\right) \quad \text { otherwise. }
\end{aligned}
$$

The first equation in (1) is the usual inter temporal condition necessary for optimality that holds when the borrowing limit does not bind. In our analysis we exploit this optimality condition in equilibrium, which we introduce below:

Definition 1: A competitive equilibrium (CE) for the previous economy is a pair $\left(a^{h}, a^{l}\right)$, and a return $R$, such that: 1$)$ given $R$ the conditions in (1)

\footnotetext{
${ }^{5}$ We thus think of the endowment in the first period as defining the agent's "type". The normalization of $\pi_{1}=1 / 2$ saves notation but is otherwise innocuous.
} 
evaluated at $c_{1}^{i}=e_{1}^{i}-a^{i}$ and $c_{2}^{i}=\bar{e}+(1+R) a^{i}$ are satisfied for $i=l, h$ and such that 2), $a^{l}+a^{h}=0$.

Under our assumption on endowments and A1 existence of equilibrium is guaranteed (see, for instance, Proposition 17.C.1 in Mas-Colell et al. 1995). Let $\left(R^{*}, a^{*}\right)$ stand respectively for the equilibrium price and amount of saving (hence $-a^{*}$ is the amount of borrowing) when the first equation in (1) holds for both types of agents (i.e., when the borrowing limit does not bind). Since $e_{1}^{l}<e_{1}^{h}$, A1 guarantees that $a^{*}>0$, thus $c_{t}^{l}<c_{t}^{h}$, for $t=1,2$. Notice in particular that if we take $B=a^{*}$, then by construction the borrowing limit does not constraint the decisions on borrowing. For future reference we define $B^{*}=a^{*}$.

The equation in (1) implicitly defines the demand and supply of assets as a function of $R$ and the endowments. Using this equation it is straightforward to show that

$$
\frac{d a^{i}}{d R}=\beta \frac{u^{\prime}\left(\bar{e}+(1+R) a^{i}\right)+(1+R) a^{i} u^{\prime \prime}\left(\bar{e}+(1+R) a^{i}\right)}{-u^{\prime \prime}\left(e_{1}^{i}-a^{i}\right)-\beta(1+R)^{2} u^{\prime \prime}\left(\bar{e}+(1+R) a^{i}\right)} .
$$

It follows from $\mathrm{A} 1$ that the denominator of the previous expression is always positive. In case $a^{i}<0$ (for the given return and endowments), then we have that $a^{\prime}(R)>0$, or that the supply of assets (bonds) unambiguously decreases with $R$. However, the slope of the demand curve of assets (when $a^{i}>0$ ) is not necessarily positive. ${ }^{6}$ To see that A1 is not enough to preclude a backward bending demand curve as a function of $R$, let $u(c)=\left(c^{1-\sigma}-\right.$ $1) /(1-\sigma)$, and assume $e_{1}^{h}+e_{1}^{l}=1=2 \bar{e}$. The unconstrained CE is such that for all $0<\sigma, R^{*}=(1-\beta) / \beta$ and $a^{*}=\beta\left(e^{h}-\bar{e}\right) /(1+\beta)$, and we have that $a^{\prime}\left(R^{*}\right) \geq 0 \Leftrightarrow \sigma \leq\left(e^{h}+\beta \bar{e}\right) /\left(e^{h}-\bar{e}\right)$. We thus introduce a new assumption that strengthens a bit A1 and prevents a negative slope in the demand of assets:

A2: $u^{\prime}\left(\bar{e}+\left(1+R^{*}\right) B^{*}\right)+\left(1+R^{*}\right) B^{*} u^{\prime \prime}\left(\bar{e}+\left(1+R^{*}\right) B^{*}\right)>0$.

A2 requires that around the unconstrained $\mathrm{CE}$, the positive wealth effect on the demand of assets associated to an increase in $R$ is relatively weaker than its substitution effect (or that consumption goods in the two periods are "gross substitutes"). It is worth clarifying that A2 does not necessarily rely on endogenous objects: continuing with the previous example, if we take $\sigma<1$ then $d a^{h} / d R>0$ for all $R$, and thus A2 is automatically satisfied. The previous example imposes assumptions stronger than needed, but it is

\footnotetext{
${ }^{6}$ The slopes of demand and supply curves of bonds appear to be reversed because we are using the return of the asset in stead of its price.
} 
reassuring to verify that under an appropriate choice of endowments, risk aversion coefficient and discount rate, assumption A2 holds. ${ }^{7}$

We are interested in $\mathrm{CE}$ such that the borrowing constraint binds for the initially poor agents. In any of such equilibria, $a^{l}=-B$ and thus $a^{h}=B$, hence the first equation necessary for optimality in (1) holds for $i=h$. This is useful because then equation (1) implicitly defines the equilibrium return on bonds $R$ as a function of $B$. We are ready to state the main results of this section.

Proposition 1: Assume A1 and A2. Then there exists $\epsilon>0$ such that for $B \in\left(B^{*}-\epsilon, B^{*}\right)$, in CE $a^{l}=-B$, and $R^{\prime}(B)>0$.

Proof: See the Appendix.

The first part of the proposition asserts that the borrowing constraint binds when $B<B^{*}$. The second part simply states that in a $\mathrm{CE}$ in which the borrowing limit binds, a larger amount of borrowing must come together with a larger amount of saving, and that can only happen if the return on saving is also larger. With this result at hand it is straightforward to show that

Proposition 2: Assume A1 and A2. Then there exists $\epsilon>0$ such that for $B \in\left(B^{*}-\epsilon, B^{*}\right)$, in $\mathrm{CE} v_{h}^{\prime}(B)>0$.

Proof: See the Appendix.

The previous proposition states that savers always benefit from the increase in $R$ that comes with the increase in the borrowing limit. Our next result is more striking:

Proposition 3: Assume A1 and A2. Then there exists $\epsilon>0$ such that for $B \in\left(B^{*}-\epsilon, B^{*}\right)$, in $\mathrm{CE} v_{l}^{\prime}(B)<0$.

Proof: See the Appendix.

To state the intuition for Proposition 3 it is useful to introduce the expression for $v_{l}^{\prime}(B)$, which we write as:

$$
v_{l}^{\prime}(B)=\left[u^{\prime}\left(c_{1}^{l}(B)\right)-\beta(1+R) u^{\prime}\left(c_{2}^{l}(B)\right)\right]-u^{\prime}\left(c_{2}^{l}(B)\right) R^{\prime}(B) B
$$

The intuition for Proposition 3 is as follows. The first term in (3) measures the net benefit from having access to a larger borrowing. This benefit is

\footnotetext{
${ }^{7}$ For completeness, strictly speaking A2 also guarantees that the unconstrained CE is locally unique. The issue of uniqueness is well known to require further assumptions and we wont discuss it further here (for more on this see for instance sections 17.D and 17.F in Mas-Colell et al. 1995).
} 
positive whenever the borrowing constraint is binding, and decreases to zero as the borrowing constraint is alleviated. We label this effect the quantity effect of $B$. There is also a price effect, due to the general equilibrium nature of our analysis and derived from the fact that equilibrium prices must adjust to variations in $B$ in order to clear the assets market: by Proposition 1 a larger $B$ requires a larger $R$ which means that the cost of issuing debt increases with $B$. The second term of (3) measures precisely this cost in utility terms. Hence, the general equilibrium effect imposes a cost on the borrowers side, and the important observation is that this cost is bounded away from zero. This is so because neither savers are satiated (they always need an extra increase in $R$ to provide the convenient increase in the amount of saving, or $R(B)^{\prime}>0$ ), nor borrowers are satiated with finite consumption $\left(u^{\prime}>0\right)$. The implication is that for all large enough borrowing limits the price effect dominates the quantity effect, and thus in equilibrium the welfare of the initially constrained agents ends up being smaller than it could be. ${ }^{8}$ It follows that a policy consisting of increasing the borrowing limit effectively alleviates the borrowing constraint of initially poor agents, but only in the beginning: after some threshold level the policy will only improve the wellbeing of relatively rich agents, and it will do so at the expense of the welfare of relatively poor agents. ${ }^{9}$ In other words, that policy will presumably defeat its purpose.

There are two important messages from the previous equilibrium analysis: First, high-type agents (or savers) benefit from a larger borrowing limit that relaxes the constraint for those agents who wish to borrow. Second, improving consumption smoothing opportunities for low-type agents (or borrowers) by increasing their borrowing limit may have a perverse effect on their welfare because of the general equilibrium effect on prices. In view of this, it is natural to ask what is the effect on aggregate welfare of enlarging the borrowing limit. We provide an answer in the following section, in which we also briefly discuss the effects of adding uncertainty.

\section{B. The stochastic case}

\footnotetext{
${ }^{8}$ Of course this does not mean that initially constrained agents always loose with a larger borrowing limit. To see this, notice that the price effect is absent when $B=0$, and thus, there only remains the positive benefit associated to the quantity effect. By construction, this is also what happens in partial equilibrium analysis.

${ }^{9}$ This is reminiscent to Gale (1974), and Aumann and Peleg (1974) showing that in a 2-trader, 2-commodity economy, one of the traders can gain by throwing away part of her endowment of one of the goods and promoting a convenient change in relative prices. A similar story applies here, with the difference that the asset market allows agents type "high" to recover their goods in the second period.
} 
We study the effects of the borrowing limit under the "veil of ignorance", that is, we look at the effect on expected welfare of a reduction in $B$ before agents know whether they are type high or type low. This ex ante perspective is appropriate because lump-sum transfers (and any other means of compensation among agents) have been ruled-out from the analysis before hand, and thus, the borrowing limit is the only available policy instrument to enhance welfare. Furthermore, the ex ante welfare notion coincides with the utilitarian notion of aggregate welfare (a weighted average of agent's welfare).

Suppose for a moment that we restore uncertainty but only about the endowment in the second period. In this case uncertainty would emphasize the role of saving as a means for consumption smoothing for precautionary reasons. ${ }^{10}$ This intuition suggests that the presence of uncertainty would reinforce the willingness to save from type-high agents, and to reduce the borrowed amount from type-low agents, but a variation in the borrowing limit would have the same price and quantity effects as in the deterministic case. ${ }^{11}$ We therefore restore uncertainty also in the first period, so that agents only know that with probability $1 / 2$ they will be type-low, and that with probability $1 / 2$ they will be type-high. We then ask whether agents would like to reduce their ability to borrow (by fixing a $B<B^{*}$ ) before the uncertainty about types is realized. The answer to this question is the content of the following proposition.

Proposition 4: Assume A1 and A2. Then there exists $\epsilon>0$ such that for $B \in\left(B^{*}-\epsilon, B^{*}\right)$, in CE $E[v(B)]>E\left[v\left(B^{*}\right)\right]$.

Proof: See the Appendix.

Contrary to the widespread wisdom that facilitating borrowing and lending improves welfare because it may help to smooth out consumption over time and states, Proposition 4 states conditions under which a too large borrowing limit is in fact undesirable. Under these conditions, ex ante welfare would be larger with a smaller borrowing limit. ${ }^{12}$ The result in Proposition 4 follows

\footnotetext{
${ }^{10}$ To obtain precautionary savings in static models it is usually assumed that $u^{\prime \prime \prime}>0$. Huggett and Ospina (1999) show that a convex marginal utility is irrelevant in infinite horizon economies, and that in these economies what is needed is a binding borrowing constraint for a positive mass of agents.

${ }^{11}$ Specifically, formal proofs for propositions 1-3 for the stochastic case can be obtained along the same lines as the ones for the deterministic case.

${ }^{12}$ Hence, Proposition 4 extends the results in Gale (1974), and Aumann and Peleg (1974) by showing that in the ex ante sense, all agents may gain by limiting the possibilities of trade in goods that are valuable in equilibrium.
} 
because for a large borrowing limit, the quantity effect is small relative to the price effect due to general equilibrium considerations. That is, the proposition follows because of the same arguments as Proposition 3, and it implies that the borrowing limit may have also perverse effects on aggregate welfare. This is the third important result of the section.

It is perhaps puzzling the implication of Proposition 4 that when transfers are not available, it is possible to construct a distorted competitive equilibrium (due to the binding borrowing constraint) in which welfare is larger than in an equilibrium in which there is no borrowing constraint (or it is so loose that it does not bind). One may rightly argue that in an economy with incomplete insurance markets there is no obvious link between the presence of a borrowing constraint and the welfare properties of the equilibrium. However, a version of Proposition 4 also holds when there is no uncertainty and thus, the result does not hinge on the presence of uninsurable uncertainty. To see this, consider again the deterministic economy in subsection 1.A, in which agents are either type-h or type-l in the first period and where they all receive $\bar{e}$ as their second period endowment. Suppose there is a benevolent central planner maximizing $\sum_{t=1}^{2} \beta^{t-1}\left\{\alpha v_{h}\left(c_{1}^{h}, c_{2}^{h}\right)+(1-\alpha) v_{l}\left(c_{1}^{l}, c_{2}^{l}\right)\right\}$ by choice of $c_{t}^{h, l} \geq 0$ for $t=1,2$, subject to feasibility: $c_{1}^{h}+c_{1}^{l}=e_{1}^{h}+e_{1}^{l}$ and $c_{2}^{h}+c_{2}^{l}=2 \bar{e}(\alpha \in[0,1]$ is the weight assigned to each type in the welfare function). The solution to the previous problem for each $\alpha \in[0,1]$ constitutes the set of efficient allocations, and it is represented with the thick line in Figure 1.

\section{** FIGURE 1 ABOUT HERE **}

Notice in particular that the utility attained by each agent under the efficient allocation when the central planner fixes $\alpha=1 / 2$ is represented by the point PO. In the allocation corresponding to PO all agents observe the same consumption, irrespectively of their type, as preferences are separable over time and they are the same for all agents. Consider now the welfare obtained in a $\mathrm{CE}$, in which the borrowing constraint is not effective $(B \geq$ $\left.B^{*}\right)$. The first fundamental welfare theorem implies that without borrowing constraints and in the absence other distortions, the utility attained by each (type of) agent is a point of the previous (efficient) utility possibility set, say the point labeled $\mathrm{CE}^{*}$. This point is purposefully represented closer to the $v_{h}$ axis than to the $v_{l}$ axis because intuitively, given the assumptions on endowments in the $\mathrm{CE}^{*}$ the utility of the saver cannot be smaller than the utility of the borrower. Notice that by construction, the measure of aggregate welfare used in Proposition 4 associated to each combination is 
proportional to the length of the arrow linking the origin with each of them. Clearly, then, aggregate welfare associated to PO is larger than the one associated to $\mathrm{CE}^{*}$ (since utility is strictly increasing and strictly concave). Suppose now that we fix $B$ slightly below $B^{*}$, so that in the new $\mathrm{CE}$ it is binding. Two implications follow: First, the binding borrowing constraint prevents welfare in the new $\mathrm{CE}$ to belong to the frontier of the welfare possibility set, and in particular, welfare must be Pareto-dominated. Second, in terms of welfare savers loose a bit (by Proposition 2), and borrowers gain a bit, since near $B^{*}$ the quantity effect is necessarily smaller than the price effect (by Proposition 3). In particular, if $B$ is close enough to $B^{*}$ (in the sense of the propositions), then the quantity effect will be negligible compared to the price effect, and since marginal utility is decreasing, the welfare gains will necessarily outweigh the welfare looses (such a combination is labeled $\mathrm{CE}^{B}$ in the figure). Hence, introducing a borrowing limit is a way to redistribute utility from lenders to borrowers and yet aggregate welfare in the $\mathrm{CE}$ increases. This fact, however, does not mean that in a competitive equilibrium it is possible to achieve the welfare associated to PO only with a convenient choice of the borrowing limit: a too small borrowing limit will deliver welfare looses for all agents, which means that aggregate welfare as a function of the borrowing limit displays an inverted U-shape (we return to this issue in Section 3.3).

\section{Infinite horizon}

An important limitation of the previous analysis is that with only two periods, it should be possible to choose an initial distribution of types such that ex ante welfare increases in face of a given variation in $B$. Furthermore, by construction all distributions have two mass points. To overcome these limitations, we use numerical methods to look at multi period versions of the previous environment in which the equilibrium is characterized by prices and quantities as usual, and a unique, endogenously determined, equilibrium distribution of types.

We follow Aiyagari (1994), Huggett (1997), and Krusell and Smith (1998) among others, and we study a production economy which admits as a particular case an exchange economy similar to the one in the preceding section. First we describe in detail the production version of the economy, and later we indicate the modifications needed to encompass the exchange version. Specifically, we assume there is a continuum of agents maximizing utility 
over an infinite horizon. In every period, agents are subject to idiosyncratic shocks of labor productivity, which can take values $s^{i}, i=h, m, l$ (for high, medium, and low productivity). These shocks follow a Markov chain with probabilities of transition given by the matrix $\Pi=\left[\pi_{i \mid j}\right]$, where $\pi_{i \mid j} \in[0,1]$ is the probability of receiving endowment $s^{i}$ in the following period provided that the agent received $s^{j}$ in the current period. Preferences over consumption are given by a CRRA index, such that the objective of the agents is to maximize $E_{0} \sum_{t} \beta^{t}\left(c_{t}^{1-\sigma}-1\right) /(1-\sigma), \beta \in(0,1), 0<\sigma \neq 1$, and where $E_{0}$ is the conditional expectations operator (the case of $\sigma=1$ corresponds to log preferences). We also assume a neoclassical technology for the production of the consumption/investment good, which uses capital and labor in efficiency units $F\left(K_{t}, L_{t}\right)=A K_{t}^{\theta} L_{t}^{1-\theta}$ ( $A$ is a scale parameter measuring total factor productivity). Capital depreciates at a constant rate $\delta \in(0,1)$, and it is the only available asset. Finally, we assume that all markets are competitive, and that insurance markets for bad realizations of the endowment of labor productivity (and other contingent contracts) are exogenously precluded. ${ }^{13}$

Using standard recursive methods, a stationary competitive equilibrium (SRCE) for this environment can be described by means of the following objects. Let $x=(a, s)$ be the amount of assets in the hands of an agent in period $t$ and her current endowment of labor productivity. Hence $x$ is the individual state in period $t$, which lies in the space $X=[-B, \hat{B}] \times\left\{s^{h}, s^{m}, s^{l}\right\}$, where as before $-B$ is the borrowing limit and where $\hat{B}$ is a large upper bound on asset holdings that in equilibrium will no be binding in any period. The aggregate state in period $t$ is denoted $\psi$, a probability measure defined over a convenient sigma algebra $\mathcal{X}$ of $X$ describing the distribution of agents over idiosyncratic states. Associated to this probability measure there is a transition function $H$ such that $\psi^{\prime}(C)=H(\psi, C)$ for all $C \in \mathcal{X}$. The interpretation is that $H(\psi, C)$ measures, given the current distribution, the mass of agents that will lie in a set $C$ in the following period. Finally, it is useful to introduce $K(\psi)$ and $L(\psi)$ to denote the aggregate amount of capital and labor as functions of the aggregate state.

Definition 2: A Recursive Competitive Equilibrium (RCE) consists of lists of functions $\{v(x, \psi), c(x, \psi), a(x, \psi)\},\{r(\psi), w(\psi)\}$, and $\{\psi, H\}$ such that:

\footnotetext{
${ }^{13}$ This setting is a general equilibrium version of the "income fluctuations problem" studied earlier by Schechtman and Escudero (1977). See also Clarida (1987), and Chamberlain and Wilson (2000).
} 
1) $\{v(x, \psi), c(x, \psi), a(x, \psi)\}$ solve the consumers problem:

$$
\begin{aligned}
v(x, \psi)= & \max _{c, a}\left\{u(c)+\beta \sum_{s^{\prime}} \pi_{s^{\prime} \mid s} v\left(x^{\prime}, \psi^{\prime}\right)\right\} \\
\text { s.t. } & c+a^{\prime}=w(\psi) s^{\prime}+(1+r(\psi)-\delta) a, \\
& c \geq 0, a^{\prime} \geq-B, \\
& \psi^{\prime}=H(\psi)
\end{aligned}
$$

2) Markets clear: $K(\psi)=\int_{X} a(x, \psi) d \psi$ and $L(\psi)=\int_{X} s(x, \psi) d \psi$;

3) $\{r(\psi), w(\psi)\}$ are competitive, hence they satisfy:

$$
r(\psi)=F_{1}(K(\psi), L(\psi)), \text { and } w(\psi)=F_{2}(K(\psi), L(\psi)) ;
$$

4) Law of motion: $H$ is generated by $a(x, \psi)$, that is, the appropriate aggregation of agents optimal decisions given the states, so that $\psi^{\prime}(C)=H(\psi, C)$ for all $C \in \mathcal{X}$.

Part 1 in the previous definition states that $v(x, \psi)$ is the value function associated to the solution of the utility maximization problem of the consumers, and that $c=c(x, \psi), a^{\prime}=a(x, \psi)$ are the optimal policies for consumption and next period asset holdings; Part 2 is the usual market clearing condition, and part 3 implies that firms maximize profits. Part 4 of the previous definition requires that the aggregate state is consistent with decision rules at the individual level. Notice that feasibility is satisfied by Walras law.

The above production economy specializes to a pure exchange economy by fixing both $\theta$ and the initial endowment of capital equal to zero. In this economy agents receive idiosyncratic endowments equal to $A s^{i}$, and capital plays no role in production. In this case we assume that to smooth out consumption agents trade a safe bond. The definition of the RCE when the exchange economy is considered is analogous to Definition 2, with market clearing requiring $\int_{X} a(x, \psi) d \psi=0, \int_{X} c(x, \psi) d \psi=\int_{X} A s d \psi$ at the equilibrium asset return $R(\psi)$. In both the production and exchange economies it is straightforward to provide a convenient definition for the time-invariant equilibrium:

Definition 3: A Stationary Recursive Competitive Equilibrium (SRCE) is a RCE characterized by a $\psi^{*}$ such that $\psi^{*}(C)=H\left(\psi^{*}, C\right)$ for all $C \in \mathcal{X}$.

In our quantitative exercise we will address the effects of the borrowing limit by comparing steady states and also by taking into account the transition from one to another. Our benchmark calibration follows Davila et al. (2005) and it is summarized by the parameter values in Table 1 .

** TABLE 1 ABOUT HERE ** 
A few comments about the calibration are in order before we continue. The value of $A$ is chosen so that output in the frictionless, complete markets version of the economy, equals one. Davila et al. (2005) report that the earnings process delivers a Gini index of 0.60 , close to the 0.61 observed in the U.S., and that the corresponding Gini index of wealth (assuming $\sigma=2$ and $B=0$ ) equals 0.853 , again very close to the actual figure of the U.S. economy. Thus, large differences in the states of the earning process and high persistence is needed to match relevant statistics of the income and wealth distribution of the U.S. economy. Finally, the choice of $\beta$ reflects that periods are measured in years, which together with the other parameters of the model produce a capital-output ratio about 3 and an equilibrium real interest rate close to the rough $4 \%$ average observed in the U.S. ${ }^{14}$

In what follows we will be mainly concerned about the effect of an increase of the borrowing limit from $B$ to $B^{\prime}$ on welfare. To this end, we use the function $\lambda\left(x, B, B^{\prime}\right)$ to measure the consumption equivalent units that would leave an agent in state $x$ in the initial steady state, to be indifferent between staying there and jumping to the new steady state. This function is implicitly defined by

$$
E\left[\sum_{t=0}^{\infty} \beta^{t} u\left(c\left(x_{t} ; \bar{p}(B)\right) \lambda\left(x, B, B^{\prime}\right)\right) \mid x_{0}\right]=E\left[\sum_{t=0}^{\infty} \beta^{t} u\left(c\left(x_{t} ; \bar{p}\left(B^{\prime}\right)\right)\right) \mid x_{0}\right],
$$

where $\bar{p}(B)=[\bar{r}(B), \bar{w}(B)]$ and $\bar{p}\left(B^{\prime}\right)=\left[\bar{r}\left(B^{\prime}\right), \bar{w}\left(B^{\prime}\right)\right]$ stand for the constant prices at each steady state. As usual, a value of $\lambda$ larger (smaller) than one indicates that the consumption of the agent in state $x$ in the initial steady state should increase (decrease) in order to leave her indifferent between steady states. The function $\mu\left(x, B, B^{\prime}\right)$, which is defined in an analogous way, goes beyond the steady states comparison and it takes into account the transition between them.

\subsection{Exchange economy}

Table 2 reports the equilibrium interest rate corresponding to several steady states differing only in the borrowing limit $B$. The table reveals that for a given borrowing limit, the interest rate decreases as the coefficient of relative risk aversion increases. That is, more risk averse societies need a smaller

\footnotetext{
${ }^{14}$ We checked that our solution algorithm replicates the results reported in Davila et al. (2005) (see Table 3 below). We refer the reader to that paper for further details about the calibration.
} 
and smaller return to saving in order to clear the asset market. This finding is consistent with the results about the risk free rate in Huggett (1993). Table 2 also reveals that for a given value of $\sigma$, the stationary interest rate increases with the borrowing limit. This second finding is consistent with Proposition 1 in the preceding section.

\section{**TABLE 2 ABOUT HERE**}

We now fix $\sigma=2$ and in Figure 2 we report the results about a steady state comparison when we increase the borrowing limit from the benchmark case of $B=1$ to $B^{\prime}=2 .{ }^{15}$ In the horizontal axes we measure the support of the distribution of assets in the initial steady state, thus the $\lambda$ 's reported in the figure correspond to the consumption equivalent units associated to each asset and productivity level. This steady state comparison reveals that all agents are better off in a steady state with a larger borrowing limit, as $\lambda$ is always above one. Hence in this example the previous Proposition 2 holds but Proposition 3 does not. It is also clear that "savers" (i.e., agents holding non negative assets, irrespectively of their labor productivity) gain more the larger is their amount of assets. This result is due to the fact that the return to saving increases with a larger borrowing limit (i.e., due to the price effect). Interestingly, the gains of low productivity agents are not monotone in their asset level. For instance, low productivity agents that are initially borrowing constrained (or close to be so) gain more than agents that initially hold zero assets. The explanation for this is that the benefits for the agents in the lower tail of the distribution of assets come from the better consumption smoothing possibilities due to the larger borrowing limit (i.e., because of the quantity effect). Nevertheless, as soon as we look at larger asset levels the positive quantity effect becomes less and less important relative to the price effect, which is negative for borrowers. Clearly, then, a larger borrowing limit has a very different effect depending on whether the agent is liquidity constrained or not. To see this from a different perspective, notice that the benefits of medium productivity agents holding the smallest level of assets are also smaller than those of the low productivity agents. The reason is that for these agents the borrowing constraint is less stringent than for low productivity agents, and thus, the quantity effect is smaller. We try to reduce the quantity effect relative to the price effect by increasing the borrowing limit from a larger initial level. When we look at the steady state comparison moving from $B=2.5$ to $B^{\prime}=3$ we find that the general shape of $\lambda$ is similar to the one in the previous example. However, we find

\footnotetext{
${ }^{15}$ That is, our benchmark case allows to borrow the yearly per capita income corresponding to the complete-markets representative-agent economy with production.
} 
that the price effect dominates the quantity effect for indebted, mediumproductivity agents, which loose about $0,5 \%$ of their consumption, and for slightly indebted low-productivity agents, who loose about $0.01 \% \cdot{ }^{16}$ Hence, welfare decreases for some agents, although borrowing constrained agents still gain with the larger $B$.

\section{** FIGURE 2 ABOUT HERE **}

For completeness we briefly report the results for welfare once the transition between steady states is properly taken into account (i.e., the $\mu$ function we introduced before). Figure 3 reports the results over a transition from $B=2.5$ to $B^{\prime}=3$. A first thing to notice is that the benefits for the high productivity agents are larger than when the transition is ignored, and that at the same time, the benefits to medium and low productivity agents are substantially smaller, or even negative (as in the steady state comparisons, in examples starting from a larger initial $B$ we find that these effects are larger). In particular, borrowing constrained agents in the initial steady state loose welfare once the transition is taken into account. These findings suggest that there are large price effects associated to the transition toward a new steady state with a larger borrowing limit, and the results about welfare are consistent with the messages discussed after propositions 2 and 3 developed in Section 2.

\section{** FIGURE 3 ABOUT HERE **}

We conclude this subsection by looking at the mass of winners and losers, which is given by the equilibrium distribution in the initial steady state. For an example with $B=2.5$ we find that the steady state (initial) distribution is such that more than $90 \%$ of the population is concentrated at the lower tail of the distribution (in the case of $B=1$ we obtain a similar figure). This is a consequence of the high persistence of the the Markov process governing labor productivity endowments and the fact that we are dealing with an endowment economy. Since in the welfare comparisons taking into account the transition we generally find that poor, low and medium-productivity agents loose, this distribution implies that there will be a large mass of agents whom will actually benefit very little, or even loose welfare, when the borrowing limit is increased. In short, this confirms that larger borrowing limits may have perverse effects on agent's welfare. We consider next the economy with production and we asses the robustness of the previous results.

\footnotetext{
${ }^{16}$ We have obtained results along these lines in other steady state comparisons not reported for reasons of space. For instance, a similar price effect, but weaker than in the $B=2.5$ to $B^{\prime}=3$ comparison, is obtained in the comparison from $B=2$ to $B^{\prime}=2.5$.
} 


\subsection{Production economy}

We begin by reporting a few basic facts at the steady state (aggregate assets, output, saving rate -defined as investment over output-, and the equilibrium interest rate $R=r-\delta$ ) of the heterogeneous-agents incomplete-markets economy described above (labeled HA). Table 3 reports the results for several values of $\sigma$ and borrowing limits, ranging from no borrowing at all and up to a large fraction of per capita income at equilibrium prices. The table also includes a characterization of the representative agent (RA) counterpart that would be obtained if markets where complete. ${ }^{17}$

\section{**TABLE 3 ABOUT HERE**}

For a given borrowing limit, reading the table from left to right we see that aggregate assets increase, and so does output and the saving rate, as risk aversion increases. We also see that the net interest rate $R$ decreases along this dimension. For a given risk aversion coefficient, moving from top to bottom we get a picture of the effect at the steady state of a larger borrowing limit. Our results suggest that assets decrease and the interest rate increases when the borrowing limit is less stringent. These findings are consistent with the results in the precautionary savings literature and with the intuition developed in Section $2 .{ }^{18}$ Notice that since labor supply is exogenously given, the reduction in aggregate capital (assets) also means that both production and wages shrink. We also see that the saving rate remains almost unchanged, with a slight tendency to decrease. Finally, for the case of $B=0$ we report the Gini coefficient of wealth distribution, which is consistent the one reported in Davila et al. (2005).

We are now ready to study the welfare effects associated to larger borrowing limits. To facilitate the comparison with the results for the exchange economies we begin by briefly looking at steady states, and latter we properly take into account the effect of the transition. ${ }^{19}$ Starting with a steady states comparison, Figure 4 reports the findings for the benchmark case with $\sigma=2$ from $B=1$ to $B^{\prime}=2$. We find that the general shape of the function $\lambda$ is similar to the one corresponding to the exchange economy: essentially, that the gains are non monotone for low levels of assets, and that

\footnotetext{
${ }^{17}$ As a reference, the economy in Davila et al. (2005) corresponds to the case of no borrowing $(B=0.0)$ and $\sigma=2$.

${ }^{18}$ Ábrahám and Cárceles-Poveda (2007) obtain similar results.

${ }^{19}$ Abstracting from transitional dynamics is specially misleading for production economies because it ignores the cost (benefit) of building up (depleting) the stock of capital.
} 
they are larger the larger are the initial asset holdings. Nevertheless, there are two outstanding differences. First, the gains are substantially smaller: in the production economy the gains in consumption in the best of the cases (for rich agents) are well below 6\%, whereas in the exchange economy a larger borrowing limit could easily represent about a $20 \%$ steady increase in consumption. Second, with the exception of liquidity constrained agents in the initial steady state (very poor, low-productivity agents), poor agents (mainly holding debt) observe looses in their stationary consumption process when the borrowing limit increases. In fact, this loss in consumption is observed even in agents holding positive amounts of assets (with a larger initial borrowing limit, such as $B=2$ or $B=2.5$, these facts are magnified). These findings suggest that the price effect is larger, and the quantity effect smaller, in production economies than in exchange economies. The explanation for this is that in the class of production economies we are considering, an increase in the borrowing limit promotes a reduction in capital such that the interest rate increases and such that the wage rate decreases (these effects are also present in Li and Sarte 2006). Thus, unlike in exchange economies where labor income is independent of the borrowing limit, in production economies the reduction in labor income harms all agents, more so the ones for whom labor income represents a larger fraction of their total income. Hence, the overall effect on an agent's welfare depends on the relative size of capital and labor income in her total income.

\section{** FIGURE 4 ABOUT HERE ** \\ ** FIGURE 5 ABOUT HERE **}

We now evaluate the dynamic effects of price changes that occur over a transition from one steady state to another with a larger borrowing limit. We find that over such a transition the stock of capital monotonically decreases toward the new steady state level. The implication of this is that during the transition the interest rate monotonically increases, and the wage rate monotonically decreases, and thus, limiting the analysis to steady state comparisons tends to overestimate the negative price effect. Figure 5 reports the results corresponding to the transition from $B=1$ to $B^{\prime}=2$ with $\sigma=2$. The comparison of Figures 4 and 5 confirm the intuition that the gains in consumption due to a larger borrowing limit are underestimated when the transition is ignored: in particular, those who gain (like rich and high-productivity agents in the initial steady state) gain more, and those who loose (like poor medium-productivity agents in the initial steady state) loose less, than what we would say by just looking at the steady state comparison. We have computed other examples, including cases in which all 
agents observe net gains from enlarging the borrowing limit. For instance, this is the case if the borrowing limit is increased from 0 to 0.5 with $\sigma=2$. In this case, the gains for the poorest agents with $s^{l}$ can be as large as $10 \%$ of their current consumption. Agents with $s^{h}$ and $s^{m}$ observe more modest gains, between $0.4 \%$ and $0.8 \%$ at low levels of wealth, but up to $2,5 \%$ of consumption at high wealth levels. Nevertheless, even if in this case there are gains for all agents irrespectively of their wealth level and productivity state, the benefits for the middle class (in terms of assets) and not so productive agents $\left(s^{m}\right)$ are smaller than those accruing to the poorer and to the sufficiently rich. We have explored several transitions under $\sigma=1$ and $\sigma=3$, and we have obtained similar results.

For completeness we also assess informally whether winners are more or less abundant than losers when the borrowing limit is increased. In Figure 6 we plot the equilibrium distribution of agents over asset levels corresponding to the steady state with $B=1$. Combining the information in this figure with that in Figure 5 which takes into account the transition, a rough assessment suggests that about one third of the population would observe losses in their consumption after enlarging the borrowing limit.

\section{** FIGURE 6 ABOUT HERE **}

Our computations suggest that in general there will be winers and losers from extending the possibilities of borrowing. The winners are primarily those agents that are initially rich enough to be able to save (i.e., for whom borrowing is irrelevant), and their benefit consist essentially of a larger return to their saving. There is a second kind of winners: those agents that would like to borrow more for consumption smoothing purposes (or that in the initial steady state will like to do so rather soon). In our calibration these agents are the very poor and they are endowed with the lowest labor productivity. Finally, the losers are those agents that in the initial steady state are not particularly interested in borrowing more (i.e., they are not borrowing constrained), but that hold negative assets (in the exchange economies), or even slightly positive assets (in the production economies). These agents are the poor, or low middle-class, and they represent a large fraction of the population. Roughly speaking, then, our results suggest that the middle class may observe substantial welfare loses from increasing borrowing limits. 


\subsection{Aggregate welfare}

We conclude by computing aggregate welfare at the steady state corresponding to several $B$, and over the transition to various $B^{\prime}$ from a fixed $B$. In the first exercises we aggregate welfare by means of the utilitarian function with weights given by the stationary $\psi$ corresponding to each steady state: $W(B)=\int v(c(x, B)) d \psi$ (notice that we introduce $B$ as an explicit argument). Table 4 reports this measure of aggregate welfare for the case of $\sigma=2$ for the exchange and the production economy.

\section{**TABLE 4 ABOUT HERE** \\ **TABLE 5 ABOUT HERE**}

It is clear that in the exchange economy aggregate welfare increases as we allow some borrowing, but after some critical level between 1 and 2 units, aggregate welfare starts to decrease again (per capita income in this economy is 1.5219). Clearly, then, the inverted U-shape holds in this aggregate comparison of steady states for the exchange economy. Aggregate welfare in the production economy behaves in quite a different way: it monotonically decreases as we increase the borrowing limit. Why are there these striking differences between the two economies? The reason is that in the exchange economy aggregate consumption is constant and independent of $B$, but in the production economy both capital and output are smaller the larger is the borrowing. As we discussed before, the reduction in capital is specially bad for agents who's labor income is the main source of income. In the examples of Table 4, the wage rate in the exchange economy is simply A, thus $w=0.273$. In the production economy the wage rate with $B=0$ is $w=0.155$, and it decreases up to a $6 \%$, for $B=2.5$ we have $w=0.146$. Thus, equilibrium distributions under larger $B$ in the production economy put more mass of agents at lower levels of wealth (like in the exchange economy), and these agents are poorer than in the exchange economy because they obtain less and less income from their labor. In Table 5 we report aggregate welfare at the steady state when we impose a positive lower bound on capital holdings. The table also reports the aggregate amount of capital. It is clear that welfare increases as we increase the minimum assets, until we reach a point between 3 and 3.5 units, which produces an average amount of capital of about 6.5 units (a positive limit of 3 units is about $200 \%$ of per capita income). After this level, welfare starts to decrease again. It is interesting to remember that for the same economy with $B=0$, Davila et al. (2005) find that the optimal (constrained efficient) amount of capital is 14.742. Like in the two periods case at the end of section 2 , it seems that 
a conveniently chosen borrowing limit may take the equilibrium allocation closer to the optimal allocation, and yet, there is ample room for policy interventions which presumably could increase welfare substantially.

The results in Tables 4 and 5 point to the optimal lower bound for asset holdings in a static sense: If the economy had to choose where to fix the lower bound, what would be the best choice in the sense of ex ante/aggregate welfare? The answer for the exchange economy is consistent with Proposition 4 , but the proposition does not hold for the production economy. A more interesting question is, given a current bound $B$, what are the welfare gains/losses associated to changing to a $B^{\prime}$ once the transition is taken into account? Figure 7 provides a partial answer to this question.

\section{** FIGURE 7 ABOUT HERE **}

In Figure 7 we take as a benchmark the aggregate welfare corresponding to the steady state with $B=0$, and we plot how aggregate welfare changes with $B^{\prime}$ when the transition to the steady state with the new $B^{\prime}$ is taken into account (aggregate welfare is measured as the integral of the value function that takes into account the transition to each of the new steady states, integrated against the stationary measure corresponding to $B=0$ ). The benchmark $B=0$ is useful because it allows us to asses the gains from borrowing in a natural way (we come back to this issue below). It is clear that utilitarian welfare increases as some borrowing is allowed. However, the gains in welfare decrease as $B^{\prime}$ increases: aggregate welfare peaks in the transition from $B=0$ to $B^{\prime}=2$, and then it decreases thereafter (we checked in particular that the welfare associated to the transition to $B^{\prime}=2.6$ is -26.626 , smaller than the one over the transition to $B^{\prime}=2.5$ which is 26.62 , which in turn is smaller than the one corresponding to $B^{\prime}=2$ ). In this dynamic sense, therefore, Proposition 4 also holds for the production economy.

The choice of the benchmark $B=0$ and restricting the analysis to increases of the borrowing limit is not arbitrary: These choices assure that for all agents in the initial distribution there is a possible choice in the consumption set once the new $B^{\prime}$ is set in place. In light of our previous findings, and those in Davila et al. (2005), it would be very interesting to study transitions motivated by a decrease in the borrowing limit, i.e., when agents are forced to reduce the amount of debt or even to end up every period with a positive amount of assets. In these cases there is a positive mass of agents in the first period that have an amount of assets that does not belong to the relevant state space under the new $B$, precisely because the borrowing limit would be 
smaller than before, and for those agent the choice set may easily be empty.

\section{Conclusion}

In this paper we show that while some borrowing and lending is desirable from a welfare perspective, equilibrium prices associated to large borrowing limits tend to harm borrowers and to benefit lenders. In particular, the effect of prices on welfare may be so large that, after a certain threshold level is reached, aggregate welfare may decrease as borrowing increases. We show these results in a variety of environments, from a two period, deterministic economy, to an infinite horizon model with production, idiosyncratic uncertainty, and incomplete insurance markets. When we compare aggregate welfare across steady states, we find that aggregate welfare for exchange economies displays an inverted U-shape as a function of the borrowing limit. This property does not hold for the production economy we examine (a calibrated version of the U.S. economy), for which we find that the highest aggregate welfare at the steady state is obtained under a large and positive lower bound for asset holdings. Once the transition from the steady state with no borrowing to some other one with borrowing is considered, we find that aggregate welfare in the production economy also displays an inverted U-shape: transiting to a new steady state with a too large borrowing limit is worse that moving to a steady state with a more stringent limit. Since our results follow from a general equilibrium effect on prices, we think that they should be relevant not only for the credit market at the household level studied in this paper, but also in other environments in which policy variables may directly affect equilibrium prices.

There is an interesting extension to this paper that is worth to consider. In Section 5.3 we find that aggregate welfare at the steady state for the incomplete markets economy with production is largest when at the individual level there is a positive lower bound for asset holdings. However, the amount of capital under the optimal lower bound for assets is still too small compared to the corresponding constrained-efficient level (Davila et al. 1995). Given this, it is natural to ask what are the policies that are able to implement as an equilibrium outcome the constrained-efficient amount of capital, which of course is Pareto superior. Beyond this, if one is to adopt a dynamic perspective, then the relevant question is What are the policies that are able to implement the constrained-efficient allocation from the current initial condition? A first issue in dealing with this question is that we 
do not know how initial conditions affect constrained-efficient allocations (in the context of production economies with incomplete insurance markets). A second difficulty has to do with the fact that the relevant policies need to assure that for all agents represented in the initial condition, the transition to the new steady state is feasible. Simple policies like a uniform lower bound on assets are very likely to fail this feasibility requirement. A deeper investigation of these issues is left for future work. 


\section{References}

Ábrahám, A., and E. Cárceles-Poveda, 2007: "Endogenous trading constraints with incomplete asset markets". Manuscript, SUNY Stony-Brook. Aiyagari, S.R., 1994: "Uninsured Idiosyncratic Risk and Aggregate Saving". The Quarterly Journal of Economics, vol. 109, pp. 659-684.

Alvarez, F., and U. Jermann, 2000: "Efficientcy, equilibrium, and asset pricing with risk of default". Econometrica, vol. 68, pp.775-797.

Alvarez, F., and U. Jermann, 2001: "Quantitative asset prices implications of endogenous solvency constraints". Review of Financial Studies, vol. 14, pp. 1117-51.

Athreya, K.B., 2002: "Welfare implications of the Bankruptcy Reform Act of 1999". Journal of Monetary Economics, vol. 49, pp. 1567-1595.

Attanasio, O., and G. Weber, 1995: "Is consumption growth consistent with intertemporal optimization? Evidence from the consumer expenditure survey" Journal of Political Economy, vol. 103, pp. 1121-57.

Aumann, R.J., and B. Peleg, 1974: "A note on Gale's example". Journal of Mathematical Economics, vol. 1, pp. 209-211.

Banerjee, A., and A. F. Newman, 1993: "Occupational choice and the process of development." Journal of Political Economy, vol. 101, pp. 274-98.

Bencivenga, V., and B.D. Smith, 1991: "Financial intermediation and endogenous growth". Review of Economic Studies, vol. 58, pp. 195-209.

Carroll, C., 1994: "How does future income affect current consumption?" The Quarterly Journal of Economics, vol. 109, pp. 111-48.

Carroll, C., 2000: "Requiem for the repreentative consumer? Aggregate implications of microeconomic consumption behavior. "The American Economic Review, vol. 90, pp. 110-115.

Chamberlain G., and C. Wilson, 2000: "Optimal Intertemporal Consumption Under Uncertainty". Review of Economic Dynamics, vol. 3, pp. 365-95. Chatterjee, S. Corbae, D. Nakajima, M., and JV Rios-Rull, 2006: "A quatitative theory of unsecured credit risk of default". Working Paper.

Clarida, R.H., 1987: "Consumption, Liquidity Constraints and Asset Accumulation in the Presence of Random Income Fluctuations". International Economic Review, vol. 28, pp. 339-51.

Conesa, J. C., and D. Krueger, 1999: "Social security reforms with heterogeneous agents". Review of Economic Dynamics, vol. 2, pp. 757-99.

Davila, J., Hong, J. H., Krusell, P., and J-V Rios-Rull, 2005: "Constrained efficiency in the neoclassical growth model with uninsurable idiosyncratic shocks". PIER Working Paper 05-023. 
Deaton, A., 1991: "Saving and liquidity constraints". Econometrica, vol. 59, pp. $1221-48$.

Gale, D., 1974: "Exchange equilibrium and coalitions: An example". Journal of Mathematical Economics, vol. 1, pp. 63-66.

Gimenez, E. L., 2003: "Complete and incomplete markets with short-sale constraints." Economic Theory, vol. 21, pp. 195-204.

Grossman, S. J., 1977: "A characterization of the optimality of equilibrium in incomplete markets." Journal of Economic Theory, vol. 15, pp. 1-15.

Haliassos, M., and C. Hassapis, 1999: "Borrowing constraints, portfolio choice and precautionary motives: Theoretical predictions and empirical complications". Society for computation in economics, WP Computing in economics and finance \# 1341.

Hart, O., 1975: "On the optimality of equilibrium when the market structure is incomplete". Journal of Economic Theory, vol.11, pp. 418-43.

Huggett, M., 1993: "The Risk-Free Rate in Heterogeneous-Agent Incomplete Insurance Economies". Journal of Economic Dynamics and Control, vol. 17, pp. 953-969.

Huggett, M., 1997: "The One-Sector Growth Model with Idiosyncratic Shocks: Steady States and Dynamics". Journal of Monetary Economics, vol. 39, pp. 385-403.

Huggett, M., and S. Ospina, 2001: "On Aggregate Precautionary Saving: When is the Third Derivative Irrelevant?" Journal of Monetary Economics, vol. 48, pp. 373-96.

Japelli, M. and M. Pagano, 1994: "Saving, growth, and liquidity constraints". The Quarterly Journal of Economics, vol. 109, pp. 83-109.

Japelli, M. and M. Pagano, 1999: "The Welfare effects of liquidity constraints." Oxford Economic Papers, vol. 51, pp.410-30.

Li, W., and P-D Sarte, 2006:: "U.S. consumer bankruptcy choice: The importance of general equilibrium effects". Journal of Monetary Economics, vol. 53, pp.613-31.

Lucas, D., 1994: "Asset pricing with undiversifiable risk and short sales constraints: Deepening the equity premium puzzle". Journal of Monetary Economics, vol. 34, pp. 325-42.

Livshits, I., MacGee, J., and M. Tertilt, 2007: "Consumer bankruptcy: A fresh start". American Economic Review, 2007, vol. 97, pp. 402-418.

Ljungqvist, L., 1993: "Economic underdevelopment. The case of a missing market for human capital". Journal of Development Economics, vol. 40, pp. 219-39.

Marcet, A., and R. Marimon, 1992: "Communication, commitment and growth". Journal of Economic Theory, vol. 58, pp. 219-249. 
Mas-Colell, A., Whinston, M.D., and J.R. Green, 1995: Microeconomic Theory, Oxford University Press.

Mateos-Planas, F.X., and G. Seccia, 2006: "Welfare implications of endogenous credit limits with bankrupcy". Journal of Economic Dynamics and Control, vol. 30, pp. 20812115.

Mookherjee, D., and D. Ray, 2002:: "Is equality stable?" The American Economic Review, vol. 92, pp.253-59.

Paxson, Ch., 1990: "Borrowing constraints and portfolio choice". The Quarterly Journal of Economics, vol. 105, pp. 533-43.

Pratap, S., and S. Rendon, 2003: "Firm investment under imperfect capital markets: A structural estimation." Review of Economic Dynamics, vol. 6, pp. 513-45.

Schechtman, J. and V.L.S. Escudero, 1977: "Some Results on An Income Fluctuations problem". Journal of Economic Theory, vol. 16, pp. 151-66.

Zeldes, S. P., 1989: "Consumption and saving: An empirical investigation." Journal of Political Economy, vol. 97, pp. 305-46.

\section{Appendix}

Proof of Proposition 1: By continuity of the first equation in (1) at $\left(a^{h}=\right.$ $\left.B^{*}, R^{*}\right)$ we can and find a $\delta_{0}>0$ such that if $\left|R-R^{*}\right|<\delta_{0}$, then $a^{h \prime}(R)>0$ (provided that $a^{h \prime}\left(R^{*}\right)>0$ by A2). Given this $\delta_{0}$ we can also find a $\delta_{1}>0$ such that if $\left|a^{h}-B^{*}\right|<\delta_{1}$, then $\left|R\left(a^{h}\right)-R^{*}\right|<\delta_{0}$. Hence we can choose $\epsilon \in\left(0, \min \left\{\delta_{1}, B^{*}\right\}\right]$ such that $a^{h \prime}(R)>0$ whenever $a^{h}>B^{*}-\epsilon$. The equation in (1) then implies that $R\left(a^{h}\right)<R\left(B^{*}\right)$ for $a^{h} \in\left(B^{*}-\epsilon, B^{*}\right)$. Take $B=B^{*}-\epsilon$, and assume, toward a contradiction, that in CE $a^{l}>-B$. Then $a^{h}>B=B^{*}-\epsilon$, and thus, $R(B)<R\left(B^{*}\right)$ provided that the equation in (1) holds for type-h agents. However, if $a^{l}>-B$ then $e^{l}-a^{l}<e^{l}+B<e^{l}+B^{*}$, hence $u^{\prime}\left(e^{l}-a^{l}\right)>u^{\prime}\left(e^{l}+B^{*}\right)$. The hypothesis implies that (1) holds with equality also for type-l agents, and thus, $\beta(1+R) u^{\prime}\left(\bar{e}-(1+R) a^{l}\right)>$ $\beta\left(1+R^{*}\right) u^{\prime}\left(\bar{e}-\left(1+R^{*}\right) B^{*}\right)$, which can only happen if $R>R^{*}$. This contradicts the fact that $R(B)<R\left(B^{*}\right)$, and thus $a^{l}=-B$. For the second statement, since equilibrium requires $a^{h}=B$, then FONC corresponding to agents type-h reads $-u^{\prime}\left(e_{1}^{h}-B\right)+\beta(1+R) u^{\prime}(\bar{e}+(1+R) B)=0$. Totally differentiating the expression and rearranging produces

$$
\frac{d R}{d B}=\frac{-u^{\prime \prime}\left(e_{1}^{h}-B\right)-\beta(1+R)^{2} u^{\prime \prime}(\bar{e}+(1+R) B)}{\beta\left(u^{\prime}(\bar{e}+(1+R) B)+(1+R) B u^{\prime \prime}(\bar{e}+(1+R) B)\right)},
$$

which can only be positive because of A1 and A2

Proof of Proposition 2: Choose an $\epsilon$ as explained in the proof of Proposition 1 , and take $B=B^{*}-\epsilon$. Proposition 1 then implies that $a^{h}=B$. Thus we 
have that $v_{h}(B)=u\left(e_{1}^{h}-B\right)+\beta u(\bar{e}+(1+R(B)) B)$. It follows that

$$
v_{h}^{\prime}(B)=-u^{\prime}\left(e_{1}^{h}-B\right)+\beta u^{\prime}(\bar{e}+(1+R(B)) B)\left[1+R(B)+R^{\prime}(B) B\right] .
$$

Since the FONC in this case reads $-u^{\prime}\left(e_{1}^{h}-B\right)+\beta(1+R(B)) u^{\prime}(\bar{e}+(1+$ $R(B)) B)=0$, it follows that $v_{h}^{\prime}(B)=u^{\prime}(\bar{e}+(1+R(B)) B) R^{\prime}(B) B$, which is strictly positive by A1 and Proposition 1

Proof of Proposition 3: Choose an $\epsilon$ as explained in the proof of Proposition 1 , and take $B=B^{*}-\epsilon$. Proposition 1 then implies that $a^{h}=B$. We have that $v_{l}(B)=u\left(e_{1}^{l}+B\right)+\beta u(\bar{e}-(1+R(B)) B)$. Differentiating with respect to $B$ and rearranging we obtain

$$
\frac{v_{l}^{\prime}(B)}{B}=\frac{V_{1}(B)}{B}-V_{2}(B),
$$

where $V_{1}(B)=u^{\prime}\left(e_{1}^{l}+B\right)-\beta(1+R(B)) u^{\prime}(\bar{e}-(1+R(B)) B)$ and where $V_{2}(B)=\beta u^{\prime}(\bar{e}-(1+R(B)) B) R^{\prime}(B)$. We will prove the result by showing that $V_{1}(B)$ is positive but monotonically declining to zero as $B$ approaches $B^{*}$ (i.e., as $\epsilon$ approaches zero), and by showing that $V_{2}(B)$ is also positive but bounded away from zero. Hence, by continuity it will follow that $v_{l}^{\prime}(B)<0$ for all $B$ sufficiently close to $B^{*}$ (i.e., $\epsilon$ sufficiently close to 0 ). $V_{1}(B)$ is the FOC of the borrower, hence it is positive for $B<B^{*}$ by Proposition 1 , and it is zero by construction for $B=B^{*}$. A1 and Proposition 1 assure that $V_{1}(B)$ is monotonically declining in $B$. Hence $V_{1}(B) / B$ can be made arbitrarily close to zero as $\epsilon \rightarrow 0 . V_{2}(B)$ is positive by $\mathrm{A} 1$ and by Proposition 1 . Notice also from (4) that

$$
R^{\prime}(B)>\frac{-u^{\prime \prime}\left(e_{1}^{h}-B\right)-\beta(1+R)^{2} u^{\prime \prime}(\bar{e}+(1+R) B)}{\beta u^{\prime}(\bar{e}+(1+R) B)},
$$

hence $V_{2}(B)>-u^{\prime \prime}\left(e_{1}^{h}-B\right)-\beta(1+R)^{2} u^{\prime \prime}(\bar{e}+(1+R) B)$, and by A1, $V_{2}(B)>-u^{\prime \prime}\left(e_{1}^{h}-B\right)$. Since $u$ is strictly concave, then for all $B \in\left[0, B^{*}\right]$ (i.e., for all finite consumption) we have that $-u^{\prime \prime}\left(e_{1}^{h}-B\right) \geq M$ for some $M>0$. Hence, the result holds for all $\epsilon \leq \epsilon_{0}$, where $\epsilon_{0}$ satisfies that $V_{1}\left(B^{*}-\epsilon_{0}\right) \leq-M$, and the proof is completed

Proof of Proposition 4: Choose $\epsilon \in\left(0, \min \left\{\delta_{1}, B^{*}\right\}\right]$ as explained in the proof of Proposition 1, and let $B=B^{*}-\epsilon$. We write $E[v(B)]=1 / 2\left(v_{h}(B)+\right.$ $\left.v_{l}(B)\right)$, where $v_{s}(B)=u\left(c_{1}^{s}\right)+\beta E\left[u\left(c_{2}^{s^{\prime}}\right) \mid s\right]$, for $s, s^{\prime}=h, l$. We will show that $v_{h}^{\prime}(B)+v_{l}^{\prime}(B)<0$ for $B$ close to $B^{*}$ (i.e., for $\epsilon$ close to zero) by applying similar arguments to those in Proposition 3. To this end, compute the derivative of $E[v(B)]$, cancel out terms using the FOC of the type-h 
consumers, and reorganize terms to get $2 E\left[v^{\prime}(B)\right]=W_{1}(B)+W_{2}(B)$, where

$$
W_{1}(B)=\beta R^{\prime}(B) B\left(E\left[u^{\prime}\left(c_{2}^{s^{\prime}} \mid h\right]-E\left[u^{\prime}\left(c_{2}^{s^{\prime}}\right) \mid l\right]\right),\right.
$$

where

$$
W_{2}(B)=u^{\prime}\left(c_{l}^{l}\right)-\beta(1+R(B)) E\left[u^{\prime}\left(c_{2}^{s^{\prime}}\right) \mid l\right]
$$

and were

$$
\frac{d R}{d B}=\frac{-u^{\prime \prime}\left(c_{1}^{h}\right)-\beta(1+R)^{2} E\left[u^{\prime \prime}\left(c_{2}^{s^{\prime}}\right) \mid h\right]}{\beta\left(E\left[u^{\prime}\left(c_{2}^{s^{\prime}}\right) \mid h\right]+(1+R) B E\left[u^{\prime \prime}\left(c_{2}^{s^{\prime}}\right) \mid h\right]\right.},
$$

holds in this version of the economy with uncertainty. Consumption in the second period depends on both, the state in the first and in the second period, which we denote as $c_{2}^{h}\left|h=e_{2}^{h}+(1+R) B, c_{2}^{l}\right| h=e_{2}^{l}+(1+R) B$, and $c_{2}^{h}\left|l=e_{2}^{h}-(1+R) B, c_{2}^{l}\right| l=e_{2}^{l}-(1+R) B$. By A1 and an appropriate version of Proposition 1, we have that $E\left[u^{\prime}\left(c_{2}^{s^{\prime}}\right) \mid h\right]-E\left[u^{\prime}\left(c_{2}^{s^{\prime}}\right) \mid l\right]<0$ for all $B \in\left(B^{*}-\epsilon, B^{*}\right)$. Furthermore, $E\left[u^{\prime}\left(c_{2}^{s^{\prime}}\right) \mid h\right]-E\left[u^{\prime}\left(c_{2}^{s^{\prime}}\right) \mid l\right]$ decreases with $B$, hence there is some $N_{1}<0$ such that $E\left[u^{\prime}\left(c_{2}^{s^{\prime}}\right) \mid h\right]-E\left[u^{\prime}\left(c_{2}^{s^{\prime}}\right) \mid l\right] \leq N_{1}$ for all $\epsilon$. Since for all $B \in\left(B^{*}-\epsilon, B^{*}\right)$ consumption in the second period is finite and bounded away from zero, it also follows that there is some $N_{2}>0$ such that for all $\epsilon, d R / d B>N_{2}$. We conclude that $W_{1}(B)<B N_{1} N_{2}$. Next, $W_{2}(B)$ is positive and can be made arbitrarily close to zero as $B$ approaches $B^{*}$ by the same arguments as in Proposition 3. Since $B=B^{*}-\epsilon$, then there is $\epsilon^{\prime}$ such that $W_{2}\left(B^{*}-\epsilon^{\prime}\right)=-\left(B^{*}-\epsilon^{\prime}\right) N_{1} N_{2}$. It follows that $2 E\left[v^{\prime}\left(B^{*}-\epsilon\right)\right]<0$ for all $\epsilon \in\left(0, \min \left\{\delta_{1}, B^{*}, \epsilon^{\prime}\right\}\right]$, and the proof is concluded 
Table 1: Parameter values.

\begin{tabular}{|c|c|c|c|c|}
\hline General & $\beta$ & $\overline{\theta \theta}$ & $\overline{A A}$ & $\bar{\delta}$ \\
\hline Parameters & 0.887 & 0.36 & 0.273 & 0.08 \\
\hline Earnings & $s \in\left\{s^{h}, s^{m}, s^{l}\right\}$ & $\{46.55$ & 5.29 & $1\}$ \\
\hline$\pi_{s \mid s^{\prime}}=$ & {$\left[\begin{array}{rr}0.917 & 0.083 \\
0.011 & 0.980 \\
0.0 & 0.008\end{array}\right.$} & $\begin{array}{r}0.0 \\
0.009 \\
0.992\end{array}$ & & \\
\hline
\end{tabular}

Table 2: Steady states, exchange economy.

\begin{tabular}{l|ccc}
$R$ & $\sigma=1$ & $\sigma=2$ & $\sigma=3$ \\
\hline$B=0$ & -.31563 & -.84648 & -.98038 \\
$B=1$ & .006 & -.15793 & -.29451 \\
$B=2$ & .04284 & -.06332 & -.1446 \\
$B=3$ & .05892 & -.02488 & -.08847 \\
\hline
\end{tabular}

Equilibrium interest rates under several borrowing limits and risk aversions. 
Table 3: Steady states, production economy.

\begin{tabular}{|c|c|c|c|c|c|}
\hline & & RA & & HA & \\
\hline & & & $\sigma=1$ & $\sigma=2$ & $\sigma=3$ \\
\hline$B=0.0$ & & & & & \\
\hline & $K$ & 1.7358 & 2.4782 & 4.0264 & 6.7238 \\
\hline & $Y$ & 1.0 & 1.1360 & 1.3537 & 1.6282 \\
\hline & & 0.1388 & 0.1744 & 0.2379 & 0.3303 \\
\hline & Gini W & & 0.8797 & 0.8567 & 0.8217 \\
\hline & $\mathrm{R}$ & 0.1273 & 0.0813 & 0.041 & 0.0071 \\
\hline$B=0.5$ & & & & & \\
\hline & $K$ & & 2.3828 & 3.8165 & 6.3432 \\
\hline & $Y$ & & 1.1208 & 1.3279 & 1.5944 \\
\hline & $s r$ & & 0.1700 & 0.2299 & 0.3182 \\
\hline & $\mathrm{R}$ & & 0.0893 & 0.0452 & 0.0104 \\
\hline$B=1.0$ & & & & & \\
\hline & $K$ & & 2.3377 & 3.6749 & 6.0489 \\
\hline & $Y$ & & 1.1131 & 1.3099 & 1.5674 \\
\hline & $s r$ & & 0.1680 & 0.2244 & 0.3087 \\
\hline & $\mathrm{R}$ & & 0.0914 & 0.0483 & 0.0132 \\
\hline$B=2.0$ & & & & & \\
\hline & $K$ & & & 3.4624 & 5.6806 \\
\hline & $Y$ & & & 1.2822 & 1.5323 \\
\hline & $s r$ & & & 0.2160 & 0.2965 \\
\hline & $\mathrm{R}$ & & & 0.0533 & 0.0188 \\
\hline$B=2.5$ & & & & & \\
\hline & $K$ & & & 3.4032 & 5.3261 \\
\hline & $Y$ & & & 1.2742 & 1.4972 \\
\hline & $s r$ & & & 0.2136 & 0.2845 \\
\hline & $\mathrm{R}$ & & & 0.0547 & 0.0211 \\
\hline$B=3.0$ & & & & & \\
\hline & $K$ & & & & 5.1560 \\
\hline & $Y$ & & & & 1.4798 \\
\hline & $s r$ & & & & 0.2787 \\
\hline & $\mathrm{R}$ & & & & 0.0233 \\
\hline
\end{tabular}

Gini W stands for the Gini Coefficient in wealth distribution. 
Table 4: Aggregate welfare $W(\sigma=2)$.

\begin{tabular}{cccccc} 
& $B=0$ & $B=0.5$ & $B=1$ & $B=2$ & $B=2.5$ \\
\hline Exchange & -18.9 & -12.8 & -12.5 & -13.3 & -14.0 \\
Production & -30.0 & -33.3 & -41.4 & -85.7 & -272.0 \\
\hline \hline
\end{tabular}

$\overline{\overline{\text { Aggregate welfare at the steady state under several borrowing }}}$ limit for the exchange and production economy.

Table 5: Aggregate welfare, $W$, and $K(\sigma=2)$.

\begin{tabular}{ccccccc} 
& $B=-0.5$ & $B=-1$ & $B=-1.5$ & $B=-2$ & $B=-2.5$ & $B=-3$ \\
\hline$W$ & -27.2686 & -25.2169 & -24.0221 & -23.2232 & -22.7382 & -22.8123 \\
$K$ & 4.2388 & 4.5324 & 4.8233 & 5.1768 & 6.0296 & 6.8123 \\
\hline \hline
\end{tabular}

$\overline{\text { Aggregate welfare and capital stock at the steady state under several "sav- }}$ ing" limits for the production economy. 


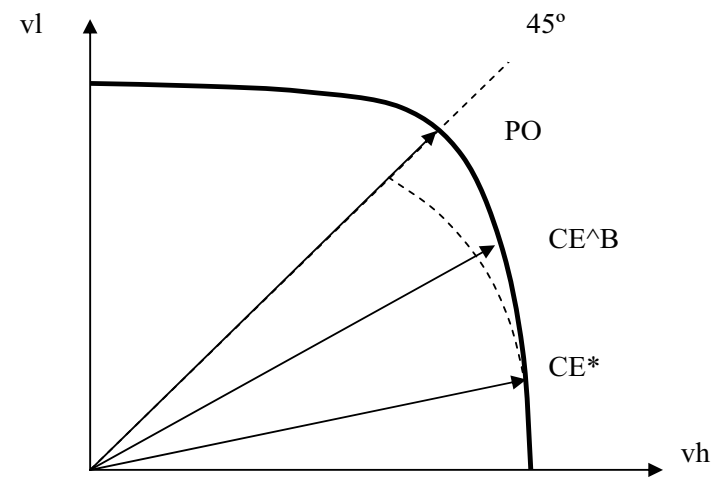

Figure 1: Aggregate welfare in a CE with a binding borrowing constraint (RCE) can be larger than with no constraint (CE), but it is smaller than in PO.

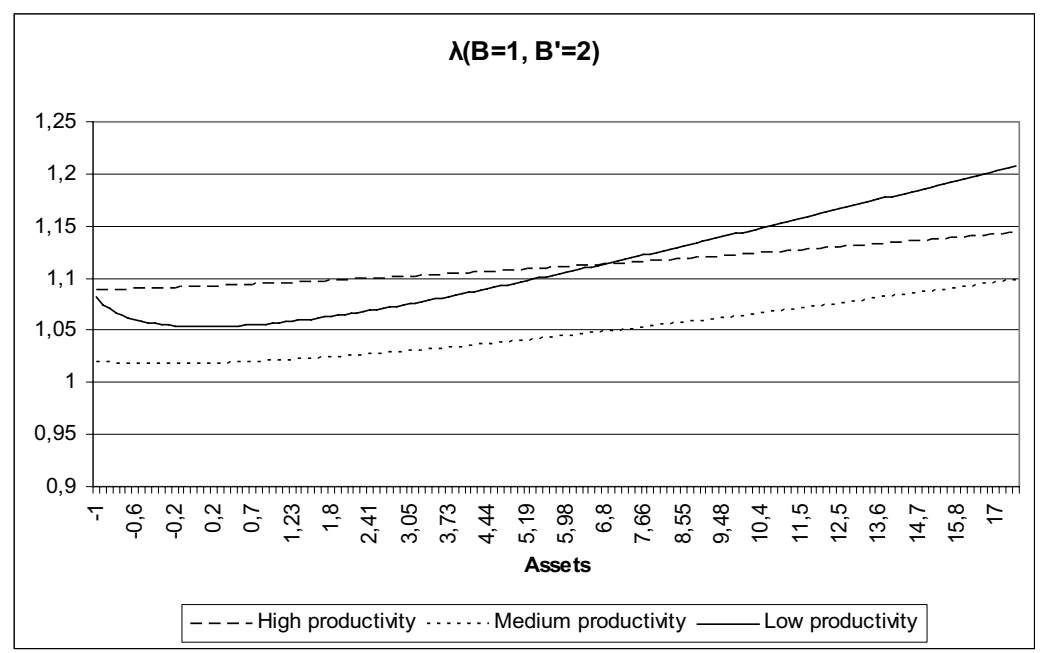

Figure 2: Consumpion equivalent units in a steady state comparison for the exchange economy. 


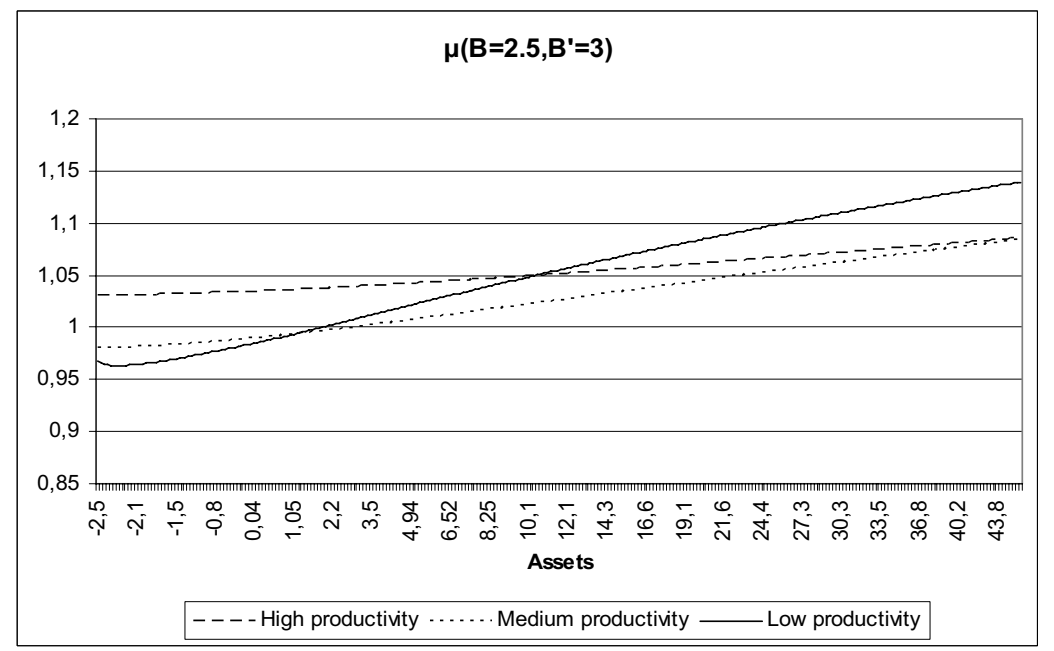

Figure 3: Consumpion equivalent units associated to the transition between steady states for the exchange economy.

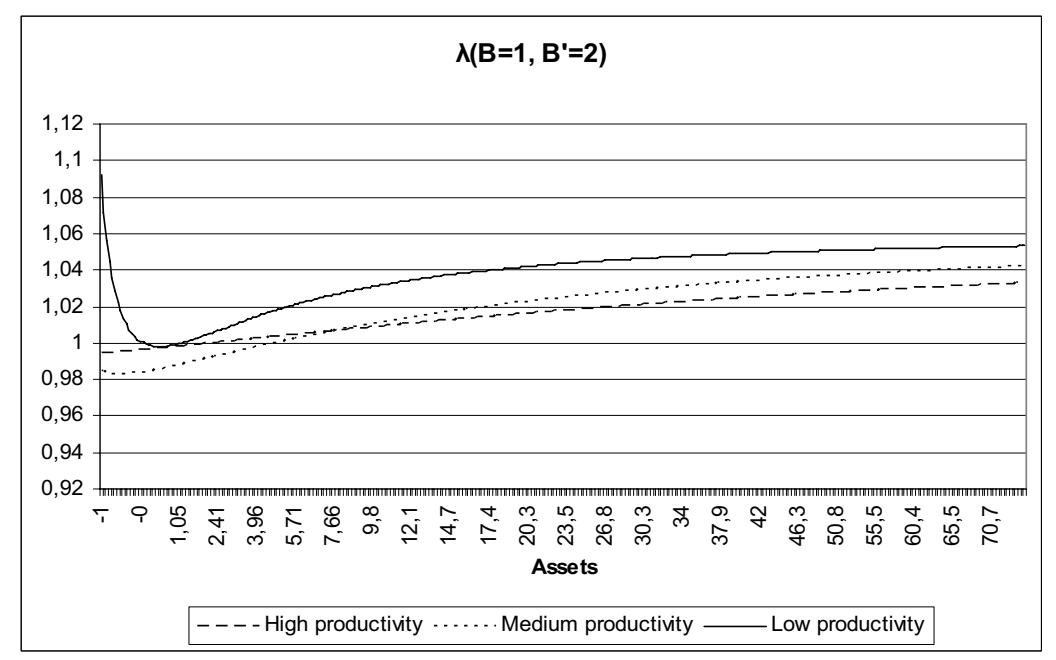

Figure 4: Consumpion equivalent units in a steady state comparison for the production economy. 


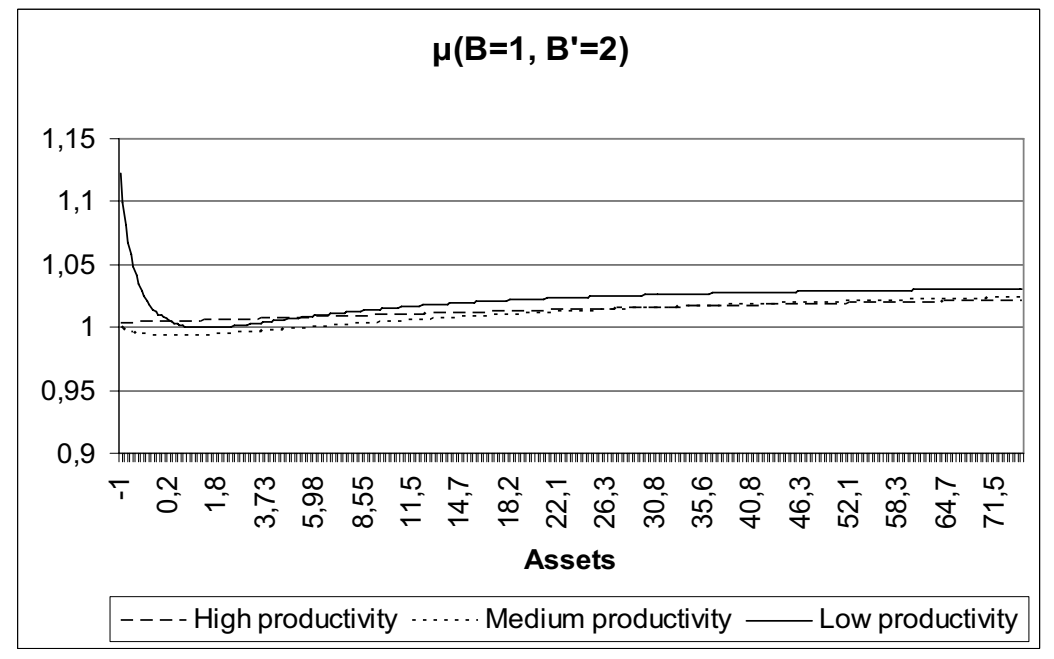

Figure 5: Consumpion equivalent units associated to the transition between steady states for the production economy.

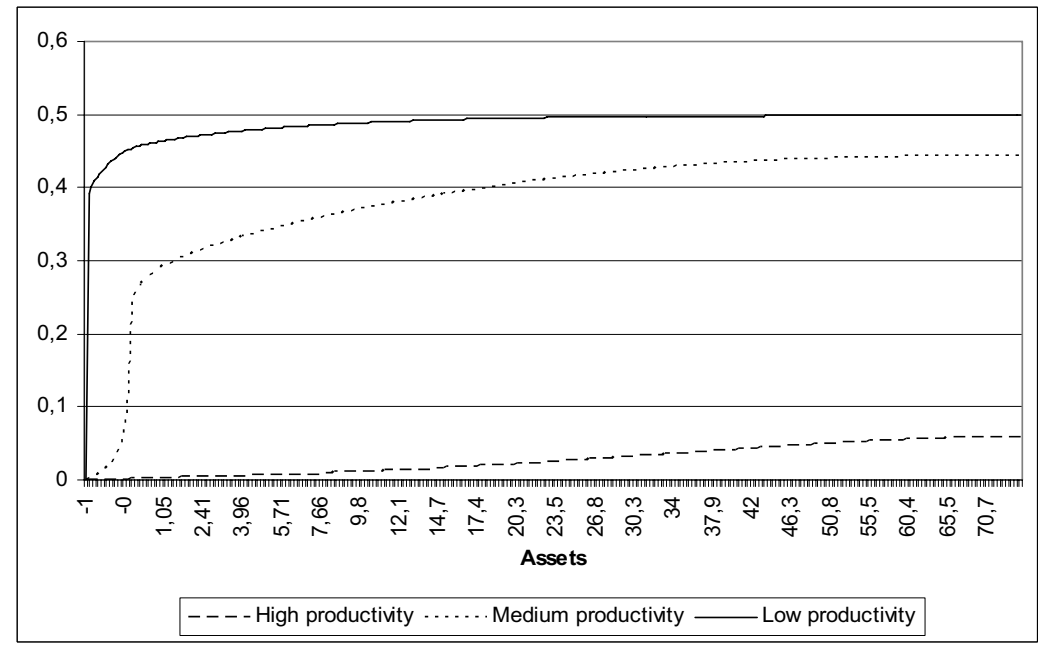

Figure 6: Equilibrium distribution of agents over assets in the steady state with $B=1$ in the production economy. 


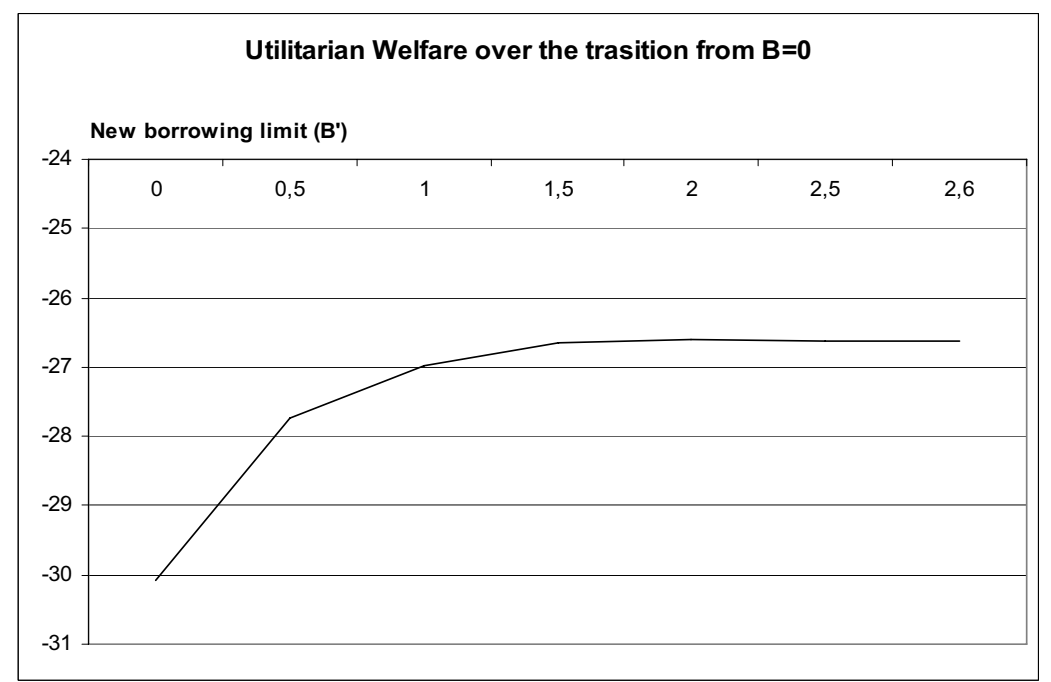

Figure 7: Aggregate welfare taking into account the transition to a larger borrowing limit displays an inverted- $U$ shape: Aggregate welfare over the transition to $B^{\prime}=2$ is larger than over any other transition. 